\title{
Extreme Weather and Climate Change Cost Assessments
}

\section{Katie Jenkins*}

Urban Systems Modeller, Environmental Change Institute, University of Oxford, Oxford, OX1 3QY, UK

Extreme weather events are considered one of the main channels through which socio-economic impacts of climate change are expected to be felt [1]. However, extreme weather events and their potential economic impacts are often excluded from models used for climate change cost assessments. A major barrier for estimating economic and social impacts of extreme weather events is that of reliable, consistent impact data [2]. In order to provide convincing projections of losses under changing climatic and socio-economic conditions Changnon [3] notes that it is essential to have a good understanding of the impacts from historical extreme weather events, with quantitative data on the impacts of past extreme weather events providing the potential to drive projections of future impacts. Yet, there is no consistent methodology for recording or calculating economic losses from extreme weather events. Damage estimates for a particular event can vary widely depending on the reporting body; the range and type of costs included; and the time in which estimates are reported (cost estimates made in the immediate aftermath of an event are prone to change, usually increasing, over time). In addition, the reporting and accuracy of loss estimates tend to improve with the scale of the event [4].

This lack of data can have implications for the economic modelling of climate change, which has been fundamental in identifying and aggregating the scale of future economic impacts, and guiding appropriate mitigation and adaptation strategies. Economic modelling is an extremely useful tool to employ as it allows climate change policies to be based around a theoretical framework and assessed by quantitative methods, something highly desirable to policy makers. As such, climate change costs assessments form a vital component in addressing the climate change problem. Since the 1990s, the most common approach for investigating costs of climate change and designing economically efficient policies has been through Cost-Benefit Analysis (CBA). In theory CBA should compare the costs (of implementing mitigation and adaptation) and benefits (from avoided damages and ancillary benefits) of climate change to emphasise the most beneficial (economically efficient) policy response [5]. Whilst the theory behind CBA is logical, in reality it is often an assessment of costs only as these are far easier to quantify than avoided damages and ancillary benefits, particularly when related to extreme weather events.

A move towards a more risk-based, multidisciplinary analysis of climate change has been fundamental in the development and use of Integrated Assessment Models (IAMs). Models that focus on just one part of the problem, such as climate or economic models, omit crucial drivers and interactions between systems that are important for the analysis of climate change, impacts, and extreme weather events. IAMs draw on multiple models usually of energy or economic systems, atmospheric chemistry and climate systems, and environmental systems. Consequently, IAMs can consider the complex and multiple dimensions of the climate system, impacts, adaptation, mitigation, and socio-economic factors, simultaneously in a consistent quantitative framework [6,7]. IAMs are considered one of the best tools available for assessing climate change impacts, the global costs of climate change, and risks [8].

However, despite the advancement of climate modelling techniques, very few IAMs consider some form of extreme weather. The exclusion of extreme weather events and their impacts from IAMs is largely attributable to the focus of most studies on global mean climate change, and the spatial and temporal resolution of climate model output [6]. Furthermore, it can be difficult to relate global model outputs, even when downscaled, to small scale problems for which the climate models were not designed [9]. Whilst progress has been made regarding the modelling of future weather extremes, as a whole, the quantification of impacts from extreme weather events, especially on non-market sectors, is still in its infancy and consistent methodologies on economic cost assessments of extreme weather events are still developing $[10,11]$.

Whilst current disaster statistics and evidence of changing trends in extreme weather events are considered to primarily reflect changing socio-economic conditions [12], climate change may start to play a more dominant role in the future. This is an ominous course as the IPCC project much greater changes in global temperature over the $21^{\text {st }}$ century, whilst e.g. the length, frequency, and/or intensity of heat waves are projected to increase over most land areas by the end of the $21^{\text {st }}$ century; the frequency of heavy precipitation events are likely to increase in the $21^{\text {st }}$ century over many areas of the globe; and there is medium confidence that droughts will intensify in the $21^{\text {st }}$ century in some seasons and areas [13].

The exclusion or limited coverage of extreme weather events, and the risks they pose, leads one to question the comprehensiveness and utility of assessments of climate change costs, and subsequent climate change policies based on them. Ignoring extreme weather events means that such estimates exclude impacts that could appreciably increase cost estimates, and arguably cause the greatest socio-economic and environmental damages. Equally, the exclusion of extreme weather events from economic cost assessments means that the potential benefits of early, stringent mitigation in the form of avoided damages will also not be recognised. Therefore, understanding not only how extreme weather events may change under future projections of climate change, but also developing techniques and models to assess the economic and social implications of such changes, is a key issue.

\section{References}

1. IPCC (2007) Climate Change 2007: The Physical Science Basis. Contribution of Working Group I to the Fourth Assessment Report of the Intergovernmental Panel on Climate Change. Cambridge University Press, Cambridge.

2. Easterling DR, Evans J, Groisman PY, Karl T, Kunkel KE, Ambenje P (2000) Observed Variability and Trends in Extreme Climate Events: A Brief Review. Bulletin of the American Meteorological Society 81: 417-425.

3. Changnon SA (2003) Present and future economic impacts of climate extremes

*Corresponding author: Katie Jenkins, Urban Systems Modeller, Environmental Change Institute, University of Oxford, Oxford, OX13QY, UK, E-mail: katie.jenkins@ouce.ox.ac.uk

Received April 24, 2013; Accepted April 25, 2013; Published April 30, 2013

Citation: Jenkins K (2013) Extreme Weather and Climate Change Cost Assessments. J Climatol Weather Forecasting 1: e104. doi:10.4172/2332-2594.1000e104

Copyright: ( 2013 Jenkins K. This is an open-access article distributed under the terms of the Creative Commons Attribution License, which permits unrestricted use, distribution, and reproduction in any medium, provided the original author and source are credited. 
Citation: Jenkins K (2013) Extreme Weather and Climate Change Cost Assessments. J Climatol Weather Forecasting 1: e104. doi:10.4172/2332$2594.1000 \mathrm{e} 104$

in the United States. Global Environmental Change Part B: Environmental Hazards 5: 47-50.

4. Muir-Wood R, Miller S, Boissonade A (2006) The search for trends in a global catalogue of normalized weather-related catastrophe losses. Hohenkammer, Germany.

5. Desslar AE, Parson EA (2006) The Science and Politics of Global Climate Change: A Guide to the Debate. Cambridge University Press, Cambridge, UK.

6. Goodess CM, Hanson C, Hulme M, Osborn TJ (2003) Representing Climate and Extreme Weather Events in Integrated Assessment Models: A Review of Existing Methods and Options for Development. Integrated Assessment 4: 145171.

7. Carter TR, Jones RN, Lu X, Bhadwal S, Conde C et al. (2007) New Assessment Methods and the Characterisation of Future Conditions. Cambridge University Press, Cambridge 133-171.

8. Stern N (2007) The Economics of Climate Change: The Stern Review. Cambridge University Press, HM Treasury, UK
9. Kundzewicz ZW Stakhiv EZ (2010) Are climate models "ready for prime time" in water resources management applications, or is more research needed? Hydrol Sci J 55: 1085-1089.

10. Hallegatte S, Hourcade JC, Dumas P (2007) Why economic dynamics matter in assessing climate change damages: illustration on extreme events. Ecological Economics 62: 330-340.

11. Pielke R (2007) Mistreatment of the economic impacts of extreme events in the Stern Review Report on the Economics of Climate Change. Global Environmental Change 17: 302-310

12. Höppe P, Pielke R (2006) Workshop Summary Report. Paper presented at the Workshop on climate change and disaster losses: Understanding and attributing trends and projections, Hohenkammer, Germany.

13. IPCC (2012) Managing the Risks of Extreme Events and Disasters to Advance Climate Change Adaptation. A Special Report of Working Groups I and II of the Intergovernmental Panel on Climate Change, Cambridge University Press Cambridge, UK. 